\title{
As matrizes teóricas da aprendizagem histórica no Brasil: um estudo compreensivo
}

\author{
Theoretical Matrices of History Learning \\ in Brazil: A Comprehensive Study
}

Letícia Mistura*

\section{RESUMO}

Neste artigo, perscruta-se um corpus de 63 trabalhos - 48 dissertações e 15 teses - que tematizam a aprendizagem histórica, advindos de programas de pós-graduação stricto sensu brasileiros, a fim de identificar seus aportes teóricos e conceituais, em um recorte temporal de 13 anos (2005-2018). Dessa incursão resulta um mapeamento compreensivo que permite visualizar a existência de três matrizes teóricas basilares dos estudos sobre aprendizagem histórica no Brasil, a saber, (1) a Teoria da História de Jörn Rüsen; (2) os estudos da History Education inglesa e (3) uma terceira via matricial, a "desviante", cujos estudos têm como aporte autores do campo da Educação e da Psicologia.

Palavras-chave: aprendizagem histórica; teoria da História; estado do conhecimento.

\section{ABSTRACT}

In this study, we examine a corpus of 63 works - 48 Masters theses and 16 doctoral dissertations - that focus on historical learning, coming from Brazilian graduate and postgraduate programs, in order to identify their theoretical and conceptual basis, in a time span of 13 years, from 2005 to 2018 . This endeavor resulted in a comprehensive mapping that allowed the visualization of three basic theoretical matrices of studies on historical learning in Brazil, namely, (1) Jörn Rüsen's Theory of History; (2) the studies of English History Education and (3) a third matrix route, a "deviant" one, whose studies are supported by authors from the fields of Education and Psychology.

Keywords: historical learning; theory of History; state of knowledge.

\footnotetext{
* Universidade de Passo Fundo (UPF), Passo Fundo, RS, Brasil. leticiamistura@gmail.com
} 
[...] a linguagem não nasce sobre um fundo de silêncio: ela nasce sobre um fundo de discurso.

(VEYNE, 1998, p. 275).

De que espaços teóricos emerge a produção sobre aprendizagem histórica no Brasil? No decorrer deste estudo, intenta-se elaborar uma resposta a essa indagação por meio de marcos indiciários construídos na relação entre os aportes teóricos manifestos por um corpus de 63 trabalhos, entre dissertações e teses, produzidos no âmbito de programas de pós-graduação stricto sensu brasileiros. ${ }^{1}$

O campo investigativo do Ensino de História tem empenhado um significativo crescimento, no Brasil, nas últimas quatro décadas. A problemática que revolve esse estudo situa-se no processo de apreensão e sintetização das "linhas de força" presentes no campo investigativo do Ensino de História brasileiro. Como já observado por outros estudos (CAIMI, 2008; BAROM; CERRI, 2013), as investigações que tematizam a aprendizagem histórica, nomeadamente provenientes, em expressiva parte, da subárea denominada Educação Histórica, que compõe os interesses investigativos da Didática da História, cresceram exponencialmente nas últimas duas décadas, sob referenciais teóricos consistentes e de forte presença no campo, tendo como base a epistemologia da disciplina de referência, a História.

Nesse sentido, justifica-se o interesse por conhecer as bases teórico-conceituais dos estudos já produzidos no Brasil acerca da aprendizagem histórica e da elaboração de um mapeamento que elucide o papel da teoria e da epistemologia da História nesses estudos e suas vinculações e diálogos internacionais. Para isso, tomou-se um corpus de 63 trabalhos - 48 dissertações e 15 teses - defendidos, no Brasil, entre os anos de 2005 e 2018, perscrutando-se seus aportes teórico e conceituais.

Para a construção do corpus, foram realizadas buscas no Catálogo de Teses e Dissertações da CAPES, utilizando-se dos termos descritores "aprendizagem histórica”, entendida aqui como a relação de interações entre estudantes e conhecimento histórico, "Educação Histórica", "aprendizagem da História" e "construção do conhecimento histórico escolar". A final seleção do corpus cumpriu as seguintes exigências: que os trabalhos estivessem situados tematicamente no campo da "aprendizagem histórica"; que contivessem algu- 
ma fase de estudo exploratório; que tivessem como universo de produção de dados instituições e contextos escolares e que estivessem circunscritos no nível da Educação Básica.

Embora tenha se operado com um recorte temporal, derivado diretamente das buscas e refinamentos na base de dados, trata-se de um cotejo notadamente temático. O olhar acerca do corpus foi sendo paulatinamente refinado no esforço de delineamento das matrizes teóricas pelas quais se pautam os estudos sobre aprendizagem histórica no Brasil, por meio das arquiteturas e marcos teóricos das produções.

Assim, foram identificadas três vertentes matriciais que, ora agindo autonomamente, ora operando articuladamente, constituem atualmente a comunidade teórico-argumentativa sobre a aprendizagem histórica no Brasil: trata-se da teoria da História de Jörn Rüsen (57 ocorrências), dos estudos da History Education inglesa (38 ocorrências) e de uma terceira via, que agrupa em si trabalhos que não se enquadram nas matrizes anteriormente citadas e que dominam teoricamente os trabalhos. Esse último grupo, que representa 6 ocorrências, tem como matriz teórica conceitos dos campos da Educação e da Psicologia, aportados nas contribuições de Jean Piaget, Lev Vygotsky e da Teoria das Representações Sociais, de Serge Moscovici.

A seguir, exploraremos cada uma das matrizes, por ordem decrescente de ocorrência nos trabalhos, a fim de recuperar brevemente seu corpo teórico-conceitual. Ao fim desse estudo, oferecemos alguns apontamentos de síntese sobre o caminho traçado pelas pesquisas do corpus em relação às matrizes a que se vinculam e as perspectivas subjacentes ao campo.

\section{A TEORIA DA HISTÓRIA DE JÖRN RÜSEN: RECEPÇÃO, DIDÁTICA DA HISTÓRIA E APRENDIZAGEM HISTÓRICA}

As contribuições do filósofo da História alemão Jörn Rüsen mostram-se de forma proeminente como aporte teórico das produções integrantes do corpus deste estudo. De fato, 57 dos 63 trabalhos o mencionam ao localizar seus marcos teóricos, articulando de forma expressiva as problemáticas sobre a aprendizagem histórica à teoria da História proposta por Rüsen. Nesta seção, propomo-nos a destacar as contribuições desse filósofo da História às reflexões acadêmicas sobre aprendizagem histórica, localizando algumas de suas prin- 
cipais premissas de discussão. Igualmente pretendemos compreender de que forma o trabalho de Rüsen tem sido positivamente recepcionado no Brasil, processo que integra diacronicamente a inserção dele como autor de base e de sua obra como principal aporte teórico das investigações acadêmicas brasileiras sobre aprendizagem histórica.

Como já manifestado por alguns de seus comentadores (CALDAS, 2008; ASSIS, 2010; MARTINS, 2016), a teoria da História de Jörn Rüsen contempla o esforço de ampliar e ocupar uma lacuna que, desde os primeiros debates que abalaram as sustentações epistemológicas da disciplina e que a levaram às crises paradigmáticas, interna e externa, ao longo do século XX, permanecia pouco visível. Rüsen publica sua teoria da História em três volumes durante os anos de 1980. É preciso, neste sentido, lembrar igualmente do espaço-produtor das elaborações teóricas do autor, um mundo pós-Segunda Guerra Mundial e tensionado pela Guerra Fria, um mundo conjuntural que, no bojo da crise epistemológica da História, a veria avançar para a crise da História escolar em diversas espacialidades, inclusive no Brasil. Em sua trilogia, composta pelas obras Razão Histórica, Reconstrução do Passado e História Viva, publicada durante os anos 1980 na Alemanha e traduzidas para a língua portuguesa durante a primeira década dos anos 2000 no Brasil, Rüsen discute os fundamentos da ciência histórica, os princípios da pesquisa histórica e as formas e funções do conhecimento histórico (subtítulos das obras nas edições brasileiras).

Em Razão Histórica (2001), o autor recupera e elabora sobre os princípios e funções da teoria da História baseada na assertiva de que o trabalho do historiador que resulta na historiografia (ou o conhecimento histórico em forma narrativa) é produção de significado - em que existe uma autorreflexão, a apreensão da realidade pelo pensamento e sua interiorização. É nessa obra que o autor localiza o pano de fundo de sua teoria. Rüsen busca caracterizar "a função prática que a teoria exerce (ou pode exercer) nos diversos campos de atividade do historiador" (2001, p. 26). Por meio desse pressuposto, o autor concebe um de seus postulados mais significativos: o de que o pensamento histórico (o pensamento produzido por meio de autorreflexão: apreensão da realidade e interiorização) é elaborado na realidade por meio de uma matriz disciplinar da ciência histórica, composta, naquela ocasião, por cinco fatores, no limiar entre a experiência da vida prática ("realidade") e a ciência especializada. 
Figura 1: A matriz disciplinar da ciência histórica

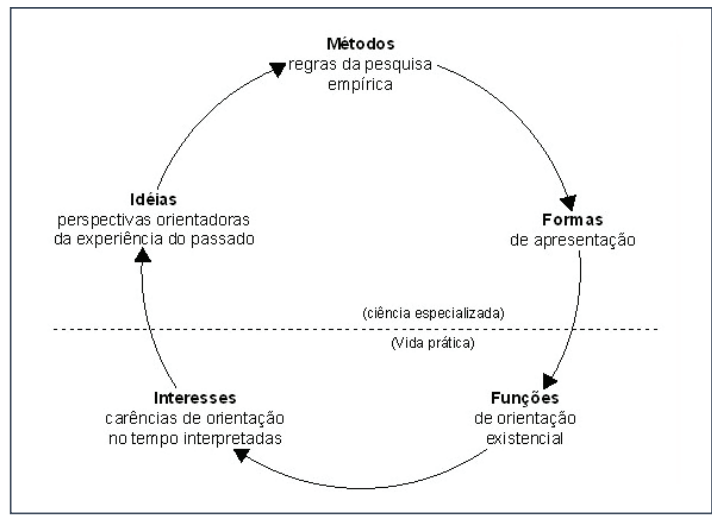

Fonte: RÜSEN (2001, p. 35)

Assim, de acordo com a matriz (Figura 1), o historiador - e o ser humano em geral - tem carências de orientação temporal, que estão arraigadas na vida prática e se constituem em interesses ou problemáticas e, no movimento da matriz - a elaboração e exposição do conhecimento histórico, metodologicamente -, transformam-se em conhecimento histórico com função de orientação existencial. Observe-se que, ao final da matriz, retorna-se à vida prática. Isso implica na concepção de que as elaborações produzidas pelos historiadores precisam apresentar-se em formas passíveis de constituírem orientação na vida prática. Oportunamente, a resposta obtida não será mais suficiente às novas carências humanas, de modo que novas interpretações precisam ser construídas.

O segundo postulado a que se deve destaque em Razão Histórica é o que versa sobre a constituição do pensamento histórico na vida prática, expressa pela assertiva de que a consciência histórica (a gestão do pensamento histórico) é fundamento da ciência histórica. Para Rüsen, o homem está constantemente interpretando a realidade - mesmo em níveis pouco complexos e cotidianamente - a fim de continuar agindo e sobrevivendo nela. Os processos de interpretação da realidade constituem-se em pensamento histórico e gestam determinadas "constituições de sentido da experiência humana no tempo" (2001, p. 59) - ou "consciências". A consciência histórica é fundamento da ciência histórica justamente porque a matriz move-se conforme as necessidades de 
orientação, em determinada realidade do tempo presente - e independe de uma concepção única de "história" - é sim um "fenômeno do mundo vital" (2001, p. 56), uma vez que produz o movimento entre carências interpretativas e interpretações orientativas.

Essa concepção leva a um derradeiro postulado, o da narrativa como construção estrutural de sentido da consciência e do pensamento históricos. De acordo com Rüsen, a narrativa é a forma expositiva geral do pensamento histórico. Portanto, “[...] é um sistema de operações mentais que definem o campo da consciência histórica.” (RÜSEN, 1987, p. 88, tradução nossa). Conforme Rüsen, a narrativa é o espaço de constituição histórica de sentido, elaborada em diferentes dimensões, interdependentes e constituintes do saber histórico: estratégia política de memória coletiva, estratégia cognitiva da produção de saber histórico e estratégia estética da poética e da retórica da representação histórica (2001, p. 163).

Em Reconstrução do passado (2007a), Rüsen explora os elementos de constituição da História como ciência, com base no pressuposto de que a ciência histórica se constitui por meio do pensamento histórico argumentativo-fundante, ou seja, com base em uma racionalidade de produção. Para tal, analisa os fatores que compõem a matriz disciplinar do conhecimento histórico - em sua função produtora da ciência histórica - por meio de sua constituição e sua metodização, incluindo as operações metodológicas da pesquisa histórica.

Em História viva (2007b), o autor analisa, em primeiro plano, as formas da historiografia, ou seja, os procedimentos por meio dos quais se produzem representações da História em caráter de constituição de sentido. Em segundo plano, tematiza as funções do conhecimento histórico, apresentando seu conceito de "didática" da História.

Em 2015, foi editada no Brasil, pela Editora da Universidade Federal do Paraná, Teoria da História: uma teoria da história como ciência, publicado pela primeira vez na Alemanha, em 2013, obra em que Rüsen concebe, na proposição de revisar, atualizar e aprofundar a sua teoria da História, "uma teoria da prática cognitiva da ciência da História” (RÜSEN, 2016, p. 32), uma vez que não se restringe à filosofia da História, mas a todas as dimensões de sua especialização: disciplinares, interdisciplinares e transdisciplinares, seus temas e funções. 
Em vista de tudo isso, quais são as contribuições efetivas de Rüsen para as pesquisas sobre aprendizagem histórica? Além de fornecer uma teoria da relação de produção de sentidos ${ }^{2}$ entre o homem e o tempo, compreensiva e relativamente "aberta" (no sentido de afetar a diferentes realidades de cultura histórica), Rüsen oferece um sistema integrado de conceitos que, advindos diretamente da discussão sobre as funções do conhecimento histórico na vida prática, são importantes à aprendizagem histórica - é da pertinência destes conceitos que reside a sua positiva recepção no Brasil.

Os pesquisadores Barom e Cerri (2013) analisam a forma como a teoria da História de Rüsen é articulada, recorrendo às conceituações elaboradas pelo autor, em dissertações e teses do campo do "ensino de História" e constatando tendências. A primeira tendência observada pelos autores é o "pensamento histórico como sinônimo de consciência histórica”, que se trata de uma apropriação teórica em que os dois conceitos não são delimitados apropriadamente, podendo ser utilizados alternadamente com o mesmo significado. Os autores apontam a necessidade de, ao utilizar-se de ambos conceitos com diferentes acepções, se esclareçam suas distinções por meio das duas conceituações, atentando-se para a função da consciência histórica no ensino de história.

Dessa última observação decorre a segunda tendência, "a possibilidade de a consciência histórica ser ou não manipulada", por meio dos processos de ensinar e aprender. Essa perspectiva sugere a "consciência histórica" como uma finalidade do processo de aprendizagem e uma estrutura que pode ser modificada de acordo com determinados procedimentos metodológicos, o que consiste em uma percepção equivocada. ${ }^{3}$ Trata-se, nesse sentido e segundo os autores, de perceber que a consciência histórica não pode ser "dirigida”, ampliada ou ensinada: a consciência histórica é uma expressão de como os indivíduos se relacionam com o passado e que significados produzem desta relação. Embora a consciência histórica esteja presente, em todo movimento do processo de aprender, é extremamente difícil que sua estrutura seja modificada ou implicada por experiências ou intervenções pontuais.

Outra tendência deriva-se igualmente da instrumentalização da consciência histórica, por meio da tentativa de qualificar/identificar ou tipificar as expressões de consciência histórica nos sujeitos das pesquisas, pela "identificação de tipologias" - o que Rüsen entende como "tipologias da consciência histórica”, que informariam níveis de competência na aprendizagem histórica. ${ }^{4}$ 
Nesse caso, as expressões de "consciência histórica" são enquadradas e tipificadas, aparentando a intenção de verificar-se a "progressão" ou a diferença entre "níveis" (aplicando-se, assim, juízos de valor entre as tipologias), apropriações que se afastam da elaboração teórica de Rüsen. Segundo Barom e Cerri (2013), não significa que determinadas enunciações da consciência histórica não possam ser tipificadas de acordo com a constituição de sentido histórico que manifestam - porém, como um próprio fenômeno do pensamento histórico (de uma época, grupo social), sem hierarquizações. Como bem lembra Ronaldo Cardoso Alves,

A relação entre o conteúdo histórico estudado, as fontes utilizadas para justificativa dos posicionamentos, as propostas de orientação e os aspectos identitários constituídos revelam aspectos importantes referentes à construção da consciência histórica na contemporaneidade. (ALVES, 2013, p. 51)

Em síntese, conhecer as expressões dos estudantes tem mais a ver com diagnóstico da construção da consciência histórica em situações de aprendizagem escolar do que com medições ou qualificações. Nesse sentido, as investigações interessadas pela tematização da consciência histórica em situações de aprendizagem cumpririam apenas uma parcela do processo de aprendizagem: a exploração das ideias dos estudantes sobre História e suas expressões de consciência histórica. Do outro lado do espectro, há o emprego efetivo dessas informações para construção de percursos de aprendizagem intencionalmente direcionados, em que se poderia observar como os estudantes operam com o conhecimento histórico que já possuem e desde suas expressões de consciência. A consciência histórica é, portanto, mediadora do processo de aprendizagem, e nesse papel reside o interesse em investigações de diagnóstico para o campo.

Por último, Barom e Cerri (2013) destacam uma quarta tendência: a "identificação das práticas de produções de sentido via narrativa histórica”, que consubstancia as pesquisas, do corpus selecionado e analisado pelos autores, ${ }^{5}$ nas quais são objeto de análise produções narrativas de estudantes como manifestação da consciência histórica, comumente por meio de instrumentos como questionários. A análise das narrativas de estudantes, nestas produções, articula principalmente dados textuais às tipologias de consciência histórica propostas por Rüsen. Aqui, os autores abrem a discussão acerca da inexistência de confronto entre o quadro teórico e os dados empíricos, o que os leva a 
refletir sobre os problemas de "enquadramento" ou ajuste forçoso dos dados às tipologias pré-determinadas, impossibilitando que se reflita acerca de teoria como hipótese ${ }^{6}$, conforme ensina Brandão (2002). Ademais, Barom e Cerri deixam aberto o debate acerca das potencialidades e dos limites em fazer uso de um instrumento de pesquisa como o questionário para "capturar" (BAROM; CERRI, 2013, p. 260) a consciência histórica, discussão que posteriormente será retomada neste estudo.

É possível notar, diante do exposto, que a positiva recepção do sistema de conceitos elaborados por Rüsen nas pesquisas sobre ensino de História ainda enfrenta desafios, especialmente relacionados às formas de emprego das conceituações pertencentes ao sistema articulado de Rüsen às pesquisas de campo. Os problemas parecem surgir da dificuldade em colocar a teoria "à prova" e perguntar-se constantemente qual é o seu lugar e quais são as funções dos conceitos fornecidos por ela nas investigações sobre ensino e aprendizagem históricos. Trata-se de uma inversão de lógica entre fenômeno e teoria: ao invés de os fenômenos desafiarem a teoria, esta tem sido refúgio dos fenômenos, abrigando-se em seu formato. Tais desafios, no entanto, são próprios do desenvolvimento de um campo investigativo: apenas a sua análise pode fazer com que o campo avance em percepção e refine as suas práticas de pesquisa.

Para finalizar esta exposição, optou-se pela articulação de dois postulados-chave de Rüsen, os que dizem respeito diretamente à aprendizagem histórica e aparecem volumosamente no corpus, "Didática da História" (em 59 das 63 produções) e "aprendizado histórico" (em 55 das 63 produções). ${ }^{7}$ Com essa incursão, pretende-se delinear conceitualmente essa matriz teórica, na qual tem-se aportado a produção acadêmica brasileira sobre aprendizagem histórica.

Rüsen (2006) recupera a concepção de "Didática da História" como uma das funções de uma teoria do conhecimento histórico ao refletir sobre a inversão de lógicas referentes às funções dos produtos do trabalho dos historiadores em dois momentos da história da historiografia: o espaço de produção histórica desde a Antiguidade até o século XVIII e a "disciplinarização" da História no século XIX. Na argumentação de Rüsen, a Didática da História - ou seja, o enraizamento da produção histórica no interesse humano em saber e memorar - consistia na orientação principal do primeiro momento da História da historiografia. Essa orientação, ao longo dos processos de especialização e cientificação da História, foram afastando-se cada vez mais da função didática da 
História e, ao mesmo tempo, afastando o conhecimento histórico da vida prática. A Didática da História foi substituída pela metodologia da pesquisa histórica: a História era produzida porque era a ciência que continha o domínio das representações de passado.

O autor utiliza-se do caso alemão para demonstrar os efeitos do afastamento da História de suas funções didáticas sociais, especialmente no que diz respeito às suas formas de ensinamento e aprendizagem, que levam o ensino de História a um colapso. Ocupar-se da reflexão sobre os processos de ensinar e aprender História é uma das funções que Rüsen atribui à sua "recuperação" da Didática da História. Os efeitos explorados pelo autor nos são conhecidos, porque também dizem respeito a contextos de anseio por mudança do ensino de História no Brasil: a concepção da História como o estudo de um passado imóvel e acabado; a narrativa política como o centro do conteúdo da disciplina de História; a memorização de fatos, nomes e datas; a passividade do estudante diante do conhecimento histórico, dentre outros. A renovação do âmbito da teoria da História, já mencionada nesta seção, adentra também a discussão curricular sobre o ensino de História na Alemanha, expandindo o conceito de "Didática da História" para abarcar "todas as formas e funções do raciocínio e conhecimento na vida cotidiana, prática” (RÜSEN, 2006, p. 12).

Na Alemanha, a discussão acadêmica em torno da Didática da História que se centra nas esferas de ensino e aprendizagem tem-se pautado nas seguintes problemáticas:

a metodologia de instrução, as funções e os usos da História na vida pública, o estabelecimento de metas para a educação histórica nas escolas e a verificação se estas têm sido atingidas, e a análise geral da natureza, função e importância da consciência histórica. (RÜSEN, 2006, p. 13)

Segundo Rüsen (2006, p. 16), o principal objeto da pesquisa da Didática da História é o aprendizado histórico, ${ }^{8}$ entendido por ele como "uma das dimensões e manifestações da consciência histórica". A consciência histórica torna-se então meio e objetivo do aprendizado histórico, uma vez que as operações mentais mobilizadas pelos estudantes produzem estruturações de consciência histórica. Por meio dessas operações também o "aprendizado histórico" acontece, formalizando experiência, interpretação e orientação (RÜSEN, 2011a).

A narrativa histórica é, para Rüsen (2011b, p. 43), uma dessas operações 
mentais que produzem "construção de sentido para a experiência no tempo". $\mathrm{O}$ autor sintetiza que, portanto, o aprendizado histórico pode ser entendido como um processo mental de construção de sentido sobre a experiência no tempo, que igualmente dá origem à orientação temporal, através da narrativa histórica (RÜSEN, 2007b). No Brasil, a concentração de produções do corpus que têm o autor Jörn Rüsen como referencial teórico encontra-se no estado do Paraná, em duas universidades: Universidade Federal do Paraná e Universidade Estadual de Londrina.

\section{A BASE INGLESA DA EDUCAÇÃO HISTÓRICA E SEUS EIXOS INTERNACIONAIS DE PRODUÇÃO}

No Brasil, o termo "Educação Histórica" designa de forma quase integral as pesquisas que tematizam a aprendizagem histórica. A expressão foi adotada pelos grupos que, desde os contextos brasileiros, vinculam-se aos pressupostos da History Education (Educação Histórica), eixo teórico que dominou a pesquisa sobre ensino e aprendizagem de História na Inglaterra, desde os anos 1970, cujas contribuições influenciaram, inspiraram e aportaram as pesquisas sobre aprendizagem histórica em diversas partes do globo. Nesta seção, se explorará a gênese e o desenvolvimento desse campo de investigação pelos estudos ingleses. A orientação de seleção de pesquisadores/contribuições para aportarmos esta exposição derivou igualmente dos indícios visualizados na incursão pelo corpus deste estudo. ${ }^{9}$

O pesquisador Peter Lee versa - em entrevista cedida junto de Rosalyn Ashby ao Instituto de Pesquisa Histórica da Universidade de Londres (LEE; ASHBY, 2009), acerca do processo de percepção sobre o que se estava ensinando na escola e ao refletir sobre a sua carreira docente, durante os anos 1960, antes de tornar-se pesquisador - afirma que eram ensinados "pedaços" de História, que não se agregavam em uma educação histórica com sentido/significado. A percepção acerca deste cenário se apurou por meio da reflexão sobre seu período de formação na Universidade de Oxford: "Eu estava apenas absorvendo informações sem ter realmente uma noção clara de que forma aquilo se agregava" (LEE; ASHBY, 2009, p. 1). Parecia não existir a intencionalidade de que, na universidade, se pensasse de fato sobre a operação histórica ou a natureza da História como conhecimento. O problema era de duas 
ordens: não se pensava por que estudava-se História e nem como era possível que a História fosse aprendida.

Peter Lee começou a trabalhar no Instituto de Educação da Universidade de Londres no final dos anos 1960. Então, alguns de seus colegas tomavam as primeiras iniciativas rigorosas no sentido de produzir investigações acerca da compreensão de crianças sobre a História. Aliando-se a Alaric Dickinson, ambos começaram, ao final dos anos 1960 e início da década de 1970, a trabalhar intensamente para construir uma base conceitual por meio da qual se pudesse pensar sobre Educação Histórica que não se definisse como estritamente piagetiana, perspectiva até então dominante. As críticas circundantes aos trabalhos que se baseavam nos estudos de Jean Piaget eram dimensionadas em dois sentidos, de acordo com Lee e Ashby (2009): ${ }^{10}$ (a) os estudos não consideravam a epistemologia da História e tratavam a narrativa histórica como unívoca e acabada; e (b) os estudos faziam uma abordagem da Teoria dos Estágios de Piaget procurando enquadrar as manifestações de pensamento histórico das crianças nos estágios piagetianos, o que impunha uma lógica de progressão linear e consecutiva que não está na base da proposta de Piaget e levava a concluir que as crianças menores de 14 anos não seriam capazes de aprender História por não terem atingido o estágio de desenvolvimento do pensamento abstrato.

O trabalho de Lee e Dickinson procurou afastar-se desse meio, intentando aportar-se principalmente em reflexões em torno do que estava sendo produzido no campo da filosofia da História, o que acabou por determinar de forma definitiva a sua contribuição para as pesquisas sobre aprendizagem histórica. O primeiro conceito elaborado por Lee e Dickinson foi o de "explicação racional" (rational explanation), produzido por meio da observação de que

[...] [as] crianças estavam fazendo suposições sobre as pessoas no passado, o que fazia com que fosse difícil para elas operar com os tipos de procedimentos explanatórios [...] que na vida cotidiana [...] funcionam perfeitamente bem. [...] Se você assumir que a maior parte do que acontece no passado é realmente ininteligível, que é o que as crianças fazem, porque [...] [o passado] é tão diferente do que faríamos, então torna-se deveras difícil trabalhar com esse tipo de explanação, de realmente fazer com que funcione. (LEE; ASHBY, 2009, p. 9, tradução nossa).

Ou seja, as crianças não deslocavam as lógicas de explicação racional de ações de sujeitos que utilizariam no dia a dia para a construção de uma expli- 
cação histórica em situação de aprendizagem. Segundo Lee (LEE; ASHBY, 2009), a explicação racional tem a ver com os tipos de argumento com os quais o sujeito justifica e explica suas ações em termos da relação entre como vê a situação e o que está posto nela, o que pretende fazer acerca dela e como elabora a ação nessa relação - que é o resultado dessas articulações. Para o pesquisador, isso parecia ser uma das bases da explicação histórica. Sem as condições de produzir explicações sobre os parâmetros de ação das pessoas no passado, as crianças não apenas consideravam o passado ininteligível, mas igualmente julgavam as pessoas do passado como ignorantes/estúpidas.

A observação dos pesquisadores inaugura o espaço para o grande postulado dos estudos de Peter Lee, Alaric Dickinson e Rosalyn Ashby, que mais tarde juntou-se às pesquisas, igualmente compartilhadas por Denis Shemilt, cujo estudo longitudinal orientou e baseou a organização curricular inglesa The School's Council History Project (SHCP). Trata-se da premissa de que o estudo do conteúdo histórico (conceitos substantivos) só pode tornar-se inteligível se operarem sobre ele dispositivos de pensamento que deem conta de abrangê-lo cognitiva e abstratamente, que os pesquisadores nomearam como "conceitos de segunda ordem". O uso do termo "de segunda ordem", segundo Lee, serve

[...] para distinguir os conceitos subjacentes implícitos na abordagem dos historiadores a qualquer conhecimento do passado, por um lado; das suas afirmações substantivas sobre qualquer parte específica do passado, por outro. Outra maneira de estabelecer isso é distinguir a História como uma forma de conhecimento ou uma "disciplina" de seu "conteúdo" - as afirmações e estórias [narrativas] sobre o passado que os historiadores produzem quando fazem História. (LEE, 2012, p. 218, tradução nossa)

Essa concepção explica a necessidade de afastamento da base teórica piagetiana e o investimento na filosofia da História que, como lugar da reflexão sobre como o conhecimento histórico é produzido, também forneceu meios de elaboração para os "conceitos de segunda ordem", que se tornaram os principais objetos de investigação para Lee e Dickinson, sob o pressuposto de que os conceitos de segunda ordem tanto organizam o conhecimento histórico quanto podem indicar os processos pelo qual os estudantes aprendem. Nesse sentido, a premissa construída pelos pesquisadores guarda um forte compro- 
misso em entender o estudante e sua interação com o conhecimento histórico como central ao processo de aprendizagem, e em refletir, ao mesmo tempo, sobre como os professores podem intervir para que os conceitos de segunda ordem efetivamente sejam processados. Em um sentido diferente, essa premissa também marca a relação íntima entre a cultura da teoria da História vigente e o ensino de História, uma vez que admite que os parâmetros para a construção do conhecimento histórico, que garantem a sua plausibilidade, podem ser semelhantes aos de compreensão e inteligibilidade desse conhecimento construído - o que significa, no mesmo passo, assumir a História como um conhecimento inacabado e sensível às problemáticas do presente.

Rosalyn Ashby complementa a argumentação:

[...] é a diferenciação entre os conceitos de segunda ordem que dão forma às particularidades individuais que se estabelece sobre o passado [...], são conceitos como explanação, mudança e continuidade que realmente permitem que algo se torne conhecimento em vez de apenas pequenas partículas de fatos. (LEE; ASHBY, 2009, p. 14, tradução nossa)

Os "conceitos de segunda ordem" nomeados pelos estudos ingleses foram gestados não apenas em interação com a filosofia da História, mas por meio de contextos intensos de pesquisa de campo. Ainda durante a década de 1970, Lee e Dickinson empreenderam ao menos duas investigações de campo, que foram usadas como a base-piloto para o Projeto CHATA (Concepts of History and Teaching Approaches, em tradução, "Concepções de História e Abordagens de Ensino"), uma importante iniciativa de pesquisa a que se dedicaram durante a década de 1990. Nos estudos iniciais, os pesquisadores precisaram produzir técnicas para que pudessem se aproximar das ideias dos estudantes. Para isso, ao adentrarem as salas de aula, a fim de realizarem pesquisas exploratórias, usaram câmeras de vídeo para registrar em filme "pequenos grupos de alunos trabalhando com problemas históricos com pouca intervenção (e eventualmente nenhuma) de adultos" (LEE, 2012, p. 219). Essa pesquisa foi desenvolvida em escolas de primeiro e segundo graus na Inglaterra (estudantes com idades entre 8 e 16 anos).

Na década de 1980, Peter Lee junta-se a Rosalyn Ashby em um projeto de pesquisa que daria as bases iniciais de sustentação para o CHATA. Durante ao menos três anos, os pesquisadores ministraram aulas e registraram em vídeo 
diversas séries e turmas (com jovens de faixa etária superior a 11 anos), utilizando o mesmo sistema de gravações em pequenos grupos e, posteriormente, gravando discussões inteiras de até 90 minutos de duração, com a ajuda dos estudantes (LEE, 2012). Aproximando-se de Denis Shemilt, concebeu-se, ao final dos anos 1980, o Projeto CHATA, desenhado para a continuação dos projetos anteriores, porém, lidando com um grupo-sujeito maior (cerca de 320 estudantes), que demandou diferentes procedimentos de pesquisa, como a construção de instrumentos que pudessem ser respondidos individualmente pelos estudantes.

Com a experiência dos projetos-pilotos anteriores, os pesquisadores puderam analisar se o que até então funcionara em classes se sustentaria em um grupo maior de participantes e por meio de conteúdos diferentes dos que até então haviam abordado. Os instrumentos produzidos contemplaram três grupos distintos de tarefas - cada uma demandava o trabalho com diferentes tipos de conceitos-chave de segunda ordem e contextos históricos. A volumosa quantidade de dados gerados durante os primeiros anos da década de 1990 possibilitou que a análise fosse operada com quatro conceitos-chave de segunda ordem: evidência, narrativa (relatos), compreensão racional e causalidade (DICKINSON; LEE, 1994). O trabalho com os conceitos de segunda ordem permitiu que, além de uma aproximação com o modo como os estudantes articulavam suas ideias, fossem construídas propostas de modelos de progressão do conhecimento histórico, sistematizando as diferentes regularidades obtidas na análise desses conceitos pelas respostas produzidas por meio dos instrumentos. Com os resultados de pesquisa divulgados em diversas partes do mundo, essa experiência singular de investigação deixou um legado de contribuições que continua inspirando e constituindo aporte teórico de pesquisas em diferentes partes do globo, alastrando-se para países como Canadá, especialmente com o pesquisador Peter Seixas; Portugal, com a pesquisadora Isabel Barca; e Brasil, onde tem se concentrado sob a liderança das pesquisadoras Marlene Cainelli e Maria Auxiliadora Moreira dos Santos Schmidt, na Universidade Estadual de Londrina e na Universidade Federal do Paraná. 


\section{A APRENDIZAGEM HISTÓRICA EM PERSPECTIVA \\ INTEGRADA: AS PRODUÇÕES “DESVIANTES”}

Verificou-se, no corpus, a tímida presença de uma “terceira via” teórico-matricial acerca da aprendizagem histórica, que se utiliza apenas em parte das contribuições das outras duas matrizes expostas nas seções anteriores. Essas produções apresentam relações entre as contribuições de Jörn Rüsen e/ou da Educação Histórica e de teorias da aprendizagem, advindas dos campos da Educação e da Psicologia. Esses estudos, que aqui classificamos como "desviantes", apresentam suas bases teóricas em três diferentes aportes: na Teoria Histórico-Cultural, de Lev Semenovich Vygotsky, na Teoria das Representações Sociais, de Serge Moscovici, e na Epistemologia Genética, de Jean Piaget.

Nesse grupo de produções "desviantes", temos 6 ocorrências, do universo de 63 trabalhos. Registra-se, novamente, o fato de que, embora elaborem seus pressupostos teóricos iniciais em outras vias, muitas delas dialogam com ao menos uma das demais matrizes, quando não com ambas. Igualmente, as contribuições teóricas em aporte pelas produções não se dão em igual grau em todos os trabalhos: em alguns cumprem natureza de premissa teórica, como forma de compreender um determinado fenômeno intrínseco à contextualização ou exposição da problemática e, em outros, acompanham o desenvolvimento teórico-metodológico integralmente, oferecendo conceitos-chave ou categorias de análise.

Optou-se por recuperar as delimitações teóricas veiculadas pelas correntes teóricas vinculadas a uma "terceira via" por meio da explanação das premissas teóricas selecionadas/elegidas pelos trabalhos que, no corpus, ancoram-se nelas. Não é o objetivo desta seção, portanto, operar uma síntese compreensiva dessas três vias matriciais, e sim, compreender como os trabalhos do corpus operam recortes teóricos sobre elas.

\section{a) Premissas das produções aportadas na Teoria Histórico-Cultural}

As produções que se aportam teoricamente na Teoria Histórico-Cultural tomam os estudos de Lev Semenovich Vygotsky (1896-1934) perfazem o grupo de maior volume dentro das produções da terceira via: são 5, de um universo de 6. Uma dessas produções baseia-se na Teoria Histórico-Cultural em 
diálogo com a Teoria das Representações Sociais da Psicologia Social. Logo, é representativa de ambas ocorrências.

Lev Vygotsky enfrenta, nas primeiras décadas do século XX, um grande projeto, ao dedicar-se à temática do pensamento e da linguagem e das relações entre pensamento e palavra, revisando os percursos teóricos e metodológicos dos principais pesquisadores da psicologia infantil e do desenvolvimento da época, perspectivando criticamente os estudos disponíveis e tecendo juntamente deles novas formulações, que, junto da proposta de um sistema de conceitos e categorias, implicarão na estrutura da Teoria Histórico-Cultural. São as contribuições-premissas de Vygotsky para a aprendizagem histórica, de acordo com os trabalhos do corpus:

a) o desenvolvimento acontece em contextos sócio-históricos - a aprendizagem acontece em contextos situados, permeados de intencionalidade, sob as tensões socioculturais;

b) a formação de conceitos pela criança e

c) a palavra como unidade de análise entre pensamento e linguagem.

A primeira contribuição, elaborada e utilizada como premissa em todos os trabalhos que abarcam a Teoria Histórico-Cultural, trata-se de seu principal pilar de existência. De acordo com Vygotsky, o desenvolvimento ontogenético, que desenvolve as funções psicológicas especificamente humanas (como a linguagem), acontece sempre em contextos de interação sociocultural. Essa assertiva está baseada em outro postulado: o de que a interação humana com objetos de conhecimento para a produção de significados não se dá de forma direta, mas mediada pela cultura.

Em termos das duas outras contribuições, uma está intimamente associada à outra. A formação de conceitos pela criança, em Vygotsky, é permeada por duas noções básicas: conceitos espontâneos e conceitos científicos. Para ele, a aprendizagem é o processo que possibilita o movimento ascendente dos conceitos espontâneos - da vivência, elaborados socioculturalmente - em direção aos científicos (produtos-síntese de redes de generalização). Esse movimento implicaria em estágios que culminassem na reorganização mental/ ressignificação social dos novos conceitos em estruturas de generalização, progressivamente, em que cada grau "superado" serve como suporte para o próximo. A natureza da formação conceitual é de sua transformação em estrutu- 
ra, uma vez que os processos não se perdem, mas culminam em elaborações mais aprofundadas a respeito de um mesmo conceito, cujo significado é ampliado. No entanto, o desenvolvimento dos conceitos científicos encontra uma natureza de percurso diversa dos espontâneos: "crescem" de cima para baixo, até encontrarem-se no campo da "experiência pessoal e da concretude" (VYGOTSKY, 2010), de onde vêm os conceitos espontâneos. O ponto de encontro dos percursos dos conceitos é justamente onde Vygotsky entende que a aprendizagem é possível: "nos ciclos já percorridos de desenvolvimento, no limiar inferior da aprendizagem” (VYGOTSKY, 2010, p. 332). É uma questão que integra aprendizagem e desenvolvimento, pois a existência de conceitos espontâneos condiciona a aprendizagem e o desenvolvimento dos conceitos científicos. A palavra, nesse sentido, é a unidade mínima em que ocorrem as transformações entre pensamento e linguagem, e, portanto, possibilita a visualização desses processos.

Trata-se de compreender, então, que as investigações que tomam as contribuições de Vygotsky e da Teoria Histórico-Cultural o fazem com base na necessidade de uma teoria do desenvolvimento e da aprendizagem, na qual esteja colocada uma proposta de desenvolvimento conceitual e uma unidade que permita a análise desse processo em contextos de aprendizagem escolarizada.

\section{b) Premissas das produções aportadas na Teoria das Representações Sociais}

A Teoria das Representações Sociais (TRS) foi elaborada no final dos anos 1950 e início da década de 1960 por Serge Moscovici, e hoje comporta uma grande teoria aberta, que se propõe a oferecer diferentes caminhos propositivos na construção de uma Psicologia Social que tenha como objeto os fenômenos sociais (mentalidade, crença, ações) como resultados de processos psicológicos e sociológicos, concebidos em sua gênese e desenvolvimento. A Teoria das Representações Sociais, como foi proposta por Moscovici, objetiva compreender "como se formam e como funcionam os sistemas de referência que utilizamos para classificar pessoas e grupos e para interpretar os acontecimentos da realidade cotidiana” (ALVES-MAZZOTTI, 1994, p. 60). Há apenas uma produção do corpus que toma a TRS como base teórica. Dela, considera especialmente o conceito central de "representações sociais".

As representações sociais consistiriam num complexo de significados 
produzidos coletivamente para dar sentido às experiências cotidianas, originando-se nas interações sociais de que fazem parte os membros de determinado grupo. Moscovici concebe as representações como processo que integra conceito e percepção em um núcleo de sentido, em estruturações de natureza própria, "teorias coletivas sobre o real" (MOSCOVICI, 1978). As representações são apropriadas pelos sujeitos em processos ontogenéticos, mas se ativam sob a forma de identidades sociais e incidem como base tanto comportamental quanto de tomadas de decisão e de posição dos indivíduos, influenciando em suas interpretações de mundo: é nesse sentido que são apropriadas por um edifício teórico de discussão sobre a aprendizagem histórica, cujos processos são condicionados pelas representações que os estudantes trazem consigo, elaboram e mobilizam em sala de aula.

\section{c) Premissas das produções aportadas na Epistemologia Genética}

Há apenas um trabalho do corpus cujo aporte teórico encontra-se, em parte, no campo da Epistemologia Genética, proposta por Jean Piaget, biólogo que deu especial atenção à integração da evolução genética humana aos processos de aquisição do conhecimento pela criança, cujos postulados deram origem a uma teoria do conhecimento. A questão central de Piaget, que se perpetua em sua obra, é compreender como se passa de um estado menor de conhecimento para um maior. As pesquisas de Piaget, no entanto, não encontraram desenvolvimento em contextos de escolarização.

A natureza de amparo teórico dos pressupostos de Piaget no corpus é, em comparação às demais produções "desviantes”, peculiar. A investigação em questão refere-se em Piaget para compreender a construção do conhecimento, atentando-se ao fato dos estudos de Piaget não comportarem necessariamente questões de didática - para isso, dá atenção aos postulados do autor por meio do diálogo teórico que os integra junto à pedagogia, adicionando à questão principal do autor as situações especificamente escolarizadas, ou seja, a construção de conhecimentos em ambientes escolares. A apropriação das contribuições de Piaget no recorte dado pela produção que, no corpus, baseia-se em sua teoria do conhecimento, se dá em articulação com o campo da didática, dialogando com autores que assumem essa integração. 


\section{ALGUMAS NOTAS PROVISÓRIAS SOBRE AS MATRIZES \\ TEÓRICAS DA APRENDIZAGEM HISTÓRICA NO BRASIL}

Neste texto, buscou-se traçar o curso das três matrizes teóricas nas quais os estudos que compõem o corpus documental deste estudo ancoram seus marcos teórico-conceituais sobre a aprendizagem histórica. Assim, a incursão perseguiu a teoria da História de Jörn Rüsen, a Educação Histórica, originária de estudos ingleses, e ainda identificou um terceiro grupo matricial que "desvia" das outras duas matrizes - e, quiçá, corresponda a uma "terceira via" de abordagem teórica sobre a aprendizagem histórica no Brasil.

Um fator que chama a atenção é a articulação, feita pelos estudos brasileiros, em grande ocorrência, das duas matrizes iniciais, que nascem de propostas teórico-metodológicas e momentos históricos distintos, porém guardam uma semelhança essencial. Tanto a matriz rüseniana quanto a matriz da Educação Histórica têm algo que as conecta intimamente, derivado da gênese dos estudos que as informam: mediante um contexto-sintomático de pulverização da História como conhecimento, foram tecidas propostas-respostas que preconizam relações mais próximas entre o ser humano e o conhecimento histórico. É a essência calcada na manutenção da força epistemológica da História como conhecimento que une e reforça os laços entre a teoria da História de Rüsen e as contribuições dos estudos da Educação Histórica.

Essa assertiva leva a aproximar-nos de uma compreensão mais profunda acerca dos motivos pelos quais tantas das produções do corpus abrigam-se sob essas duas matrizes: ao seu modo, ambas perfazem duas grandes respostas à crise do ensino de História e desta como conhecimento, a partir da segunda metade do século XX. Em contextos de perda de sentido da orientação histórica e da História como monopólio das representações do passado, ambas oferecem respostas à viabilidade, necessidade e possibilidade do conhecimento histórico constituir, em processos de ensino e aprendizagem, sentido.

Igualmente pode-se inferir algumas possibilidades sobre a natureza do lugar que ocupam, dentre os pressupostos teóricos, as contribuições advindas de outros campos disciplinares pelos trabalhos "desviantes": a necessidade de obter base conceitual e teórica nas discussões sobre aprendizagem e desenvol- 
vimento e a procura pelas contribuições advindas de lugares interdisciplinares que dão atenção direta a estes processos e fundamentam investigações no campo da Educação há décadas. Ainda que nomeadas nessa exposição como “desviantes" (em relação à expressividade das duas outras matrizes), entendemos a atitude desses estudos como a abertura de um diálogo frutuoso com o campo da Educação e seu respaldo teórico, que indiscutivelmente deve fazer parte de práticas de pesquisa sobre processos de aprendizagem.

Provocamos, nesse sentido, a inflexão: certamente é possível estudar processos de aprendizagem sem conteúdo epistemológico da História como ciência. No entanto, será possível investigar a aprendizagem histórica sem estudo sobre processos de ensino e de aprendizagem? Trata-se de uma pergunta de grande complexidade, que só pode ser enfrentada por este campo em vivaz desenvolvimento.

\section{REFERÊNCIAS}

ALVES, Ronaldo Cardoso. História e vida: o encontro epistemológico entre Didática da História e Educação Histórica. História \& Ensino, v. 19, p. 49-69, 2013.

ALVES-MAZZOTTI, Alda Judith. Representações sociais: aspectos teóricos e aplicações à educação. Em Aberto, Brasília, v. 14, n. 61, p. 60-78, jan./mar. 1994.

ASSIS, Arthur. A teoria da história de Jörn Rüsen: uma introdução. Goiânia: Editora UFG, 2010.

BAROM, Wilian Carlos Ciprioni; CERRI, Luis Fernando. Contribuições de Rüsen em ensino de História nas pesquisas de pós-graduação. In: SILVA, Cristiani Bereta da; ZAMBONI, Ernesta. (Orgs.). Ensino de História, memória e culturas. Curitiba: CRV, 2013.

BRANDÃO, Zaia. Pesquisa em Educação: conversas com pós-graduandos. Rio de Janeiro: Ed. Pontifícia Universidade Católica do Rio de Janeiro, 2002.

CAIMI, Flávia Eloisa. Novas conversas e antigas controvérsias: um olhar sobre a historiografia do ensino de história. In: OLIVEIRA; Margarida Maria Dias; CAINELLI, Marlene Rosa; OLIVEIRA, Almir Félix Batista de. (Org.). Ensino de História: múltiplos ensinos em múltiplos espaços. Natal: EDUFRN, 2008.

CALDAS, Pedro Spinola Pereira. A arquitetura da teoria: o complemento da trilogia de Jörn Rüsen. Fênix - Revista de História e Estudos Culturais, v.5, n.1, p. 1-9, 2008.

CERRI, Luis Fernando. Cartografias Temporais: metodologias de pesquisa da cons- 
ciência histórica. Educação e Realidade, Porto Alegre, v. 36, n.1, p. 59-81, jan./abr., 2011.

DICKINSON, Alaric; LEE, Peter. Investigating progression in children's ideas about History. In: JOHN, Peter; LUCAS, Peter (Ed.). Partnership and progress: new developments in History Education and History Teaching. Divison of Education: University of Sheffield, 1994.

LEE, Peter. History Education - some thoughts from the UK. [Entrevista cedida a] Cristiani Bereta da Silva. Tempo e Argumento: Revista do Programa de Pós-Graduação em História (UDESC), Florianópolis, v. 4, n. 2, p. 216 - 250, jul/dez. 2012.

LEE, Peter; ASHBY, Rosalyn. History in Education Project 2009-10. [Entrevista cedida a] Nicola Sheldon. Institute of Historical Research: University of London, 2009.

MARTINS, Estevão de Resende. Entrevista com o Prof. Dr. Estevão Chaves de Rezende Martins (Universidade de Brasília). [Entrevista cedida a] Luís Sérgio Duarte. Revista de Teoria da História, v. 16, n. 2, p. 279-279, 2016.

MOSCOVICI, Serge. A representação social da psicanálise. Rio de Janeiro: Zahar, 1978.

RÜSEN, Jörn. Historical narration: foundation, types, reason. History and Theory, vol. 26, n. 4, p. 87-97, 1987.

RÜSEN, Jörn. Razão histórica: teoria da história: os fundamentos da ciência história. Brasília: Editora UnB, 2001.

RÜSEN, Jörn. Reconstrução do passado: teoria da história II: os princípios da pesquisa histórica. Brasília: Editora UnB, 2007a.

RÜSEN, Jörn. História viva: teoria da história III: formas e funções do conhecimento histórico. Brasília: Editora UnB, 2007b.

RÜSEN, Jörn. Didática da história: passado, presente e perspectivas a partir do caso alemão. Práxis Educativa, Ponta Grossa, v. 1, n. 2, p. 07-16, jul-dez. 2006.

RÜSEN, Jörn. Aprendizado histórico. In: SCHMIDT, Maria Auxiliadora; BARCA, Isabel; MARTINS, Estevão de Rezende. Jörn Rüsen e o ensino de História. Curitiba: Ed. UFPR, 2011a.

RÜSEN, Jörn. O desenvolvimento da competência narrativa na aprendizagem histórica: uma hipótese ontogenética relativa à consciência moral. In: SCHMIDT, Maria Auxiliadora; BARCA, Isabel; MARTINS, Estevão de Rezende. Jörn Rüsen e o ensino de História. Curitiba: Ed. UFPR, 2011 b.

RÜSEN, Jörn. Teoria da história: uma teoria da história como ciência. 1. reimp. Curitiba: Editora UFPR, 2016.

VEYNE, Paul. Como se escreve a história. 4.ed. Brasília: UnB, 1998.

VYGOTSKY, Lev Semenovich. A construção do pensamento e da linguagem. 2. ed. 2. tir. São Paulo: Editora WMF Martins Fontes, 2010. 


\section{NOTAS}

${ }^{1} \mathrm{O}$ presente estudo integra a dissertação de mestrado "Entre tensões e proposições: um estado do conhecimento sobre aprendizagem histórica no Brasil em teses e dissertações", que contou com auxílio/financiamento da CAPES (Coordenação de Aperfeiçoamento de Pessoal de Nível Superior).

2 Jörn Rüsen entende "sentido" como "produto do espírito humano, mediante o qual o mundo em que o homem vive adquire um significado viabilizador de vida” (RÜSEN, 2016, p. 42), elaborado na reflexão humana acerca das tensões entre experiência e realidade. A produção de sentido, aqui, informa a orientação, na medida em que atua como critério de regulação na ação (informada, intencional) do homem na cultura. Rüsen (2016) opera com uma sequência de quatro movimentos mentais constituições de sentido: experiência, interpretação, orientação e motivação. A constituição de sentido que deriva desse processo pode ser apreendida e conhecida, de acordo com o autor, na apresentação do saber histórico em lógica narrativa. A narrativa (e a narrativa histórica) não é, entretanto, a única forma de constituir sentido à experiência - mas é aquela em que, de acordo com Rüsen, a sustentação das relações produzidas sobre o tempo pode ser elaborada de maneira peculiar. A historiografia, nesse sentido, é uma formulação peculiar de constituição histórica de sentido.

${ }^{3}$ Esta concepção também é desenvolvida em Cerri (2011).

${ }^{4}$ Em sua formulação atualizada, Rüsen (2016) reconstituiu esses níveis em uma "espiral ontogenética". Anteriormente, classificava-os em quatro níveis de desenvolvimento: tradicional, exemplar, crítico e genético. Em sua revisão, identifica-os como três: tradicional, exemplar e genético. Na espiral ontogenética, os três níveis encontram-se em ordem evolutiva (tradicional-exemplar-genético), sendo atravessados pela constituição crítica de sentido, que torna possível a passagem de um nível a outro. Essa passagem se dá no desenvolvimento cognitivo humano, estudado pela psicologia evolutiva. Rüsen define como um "déficit" desses estudos a relação com a consciência histórica, que estacionou, segundo o autor, no conhecimento da fase exemplar de desenvolvimento. De acordo com Rüsen, há ainda outra fase, a genética: "somente esta forma de interpretação leva adequadamente em conta o pensamento histórico especificamente moderno" (RÜSEN, 2016, p. 255). Rüsen chama a atenção para a natureza de progressão não-exclusiva desse desenvolvimento: "um tipo não desaparece, simplesmente, no nível do outro" (RÜSEN, 2016, p. 255), não tornando um nível passado disfuncional e inativo, mas convivendo no pensamento, uma vez que cada nível pressupõe uma função específica na orientação temporal de sentido (eternização, especialização, temporalização). A relação dessa espiral com a aprendizagem histórica é complexa, uma vez que ela serve inicialmente à compreensão da articulação e produção de sentido entre o conhecimento histórico e a experiência humana, oferecendo mais um diagnóstico acerca do pensamento histórico do que um fluxograma de seu desenvolvimento.

${ }^{5} \mathrm{O}$ corpus selecionado foi elaborado por meio de um recorte temporal, de 2001 a 2009, das pesquisas do campo do ensino de História que apresentavam a teoria da História de Jörn 
Rüsen como referencial, e elaborado com ajuda da ferramenta de busca do Google Acadêmico (https://scholar.google.com.br/).

${ }^{6}$ Zaia Brandão (2002) discorre sobre um quadro sintomático muito expressivo na pesquisa em Educação: a utilização da teoria como explicação do real. A autora aporta seu argumento na observação do grande prestígio de fórmulas teóricas que, na área da educação, se expressam como matrizes exaustivas de "explicação" de contextos-fenômeno. A autora não pretende pôr em questão a fecundidade de um referencial teórico denso para o tratamento de problemáticas de pesquisa, mas chamar a atenção às supervalorizações, modismos ou exclusivismos teórico-metodológicos que permeiam o campo produtivo da Educação, derivando pobreza analítica e enquadramento teórico de contextos reais e dificultando o avanço na compreensão do alcance de determinadas teorias para a compreensão efetiva dos fenômenos. Tem-se tratado, de acordo com Brandão, a teoria como um dado "acabado", sem possibilidades de crítica, contestação e produção para aquém dela mesma. A perspectiva que sugere é a teoria "como hipótese" de compreensão do real - toda vez que se volta a teoria dos "clássicos", segundo Brandão, não se volta à mesma teoria, pois são os contextos-problema que devem reger reflexões a respeito da teoria, não o contrário.

${ }^{7}$ A teoria da História de Jörn Rüsen contempla um sistema complexo de muitos conceitos em constante e intrincada articulação. Embora se tenha escolhido explorar esses dois conceitos, é preciso observar que: (a) as produções do corpus articulam muitos outros dos conceitos de Rüsen em diversas formas de abordagem e argumentação - estes foram selecionados por mais se aproximarem das tessituras teóricas que, no corpus, diretamente dizem respeito à aprendizagem histórica, sua temática-geradora e (b) é quase impossível deter-se, pelas condições já aludidas, a apenas esses dois conceitos ao explanar sobre eles. Portanto, outros acompanham essa incursão, aos quais não foi dedicado igual compromisso de esclarecimento.

${ }^{8}$ Nesta seção, utiliza-se o termo "aprendizado histórico" como sinônimo de "aprendizagem histórica”, por ser assim a grafia traduzida do termo, nos textos de Jörn Rüsen.

${ }^{9}$ Claramente, não se intenta esgotar as discussões em Educação Histórica dos eixos categorizados, tampouco se objetiva adentrar densamente nas produções e contribuições de cada um dos pesquisadores aqui mencionados, esforço que demandaria uma sistematização que não está correntemente em nossa alçada. O objetivo dessa categorização é justamente a visualização dos "pontos de partida" (ou matrizes) teóricos pelos quais os trabalhos do corpus ancoram-se, destacando alguns de seus principais pressupostos.

${ }^{10} \mathrm{Em}$ sua tese, a pesquisadora Lis Cercadillo apresenta um quadro adensado dos estudiosos de base piagetiana que, durante os anos de 1960 e 1970, investigaram sobre a aprendizagem histórica de estudantes. O trabalho encontra-se disponível em: https://core.ac.uk/download/pdf/83894.pdf. Acesso em: 20 ago. 2020.

Artigo recebido em 31 de agosto de 2020. Aprovado em 13 de outubro de 2020. 